\title{
1 Influence of contextual variables on styles of play in soccer
}

2 Javier Fernandez-Navarro ${ }^{\mathrm{a} *}$, Luis Fradua ${ }^{\mathrm{a}}$, Asier Zubillaga ${ }^{\mathrm{b}}$ and

3 Allistair P. McRobert ${ }^{\mathrm{c}}$

$4 \quad{ }^{a}$ Department of Physical Education and Sport, University of Granada, Granada,

5 Spain; ${ }^{b}$ Department of Physical Education and Sport, UPV/EHU University of the

6 Basque Country, Vitoria-Gasteiz, Spain; ${ }^{\circ}$ The Football Exchange, Research Institute

7 for Sport and Exercise Sciences, Liverpool John Moores University, Liverpool, UK

8

9 *Javier Fernandez-Navarro

10 Address: Faculty of Sport Sciences. Carretera de Alfacar s/n 18011, Granada, Spain.

11 Telephone: +34 958244370. Email: javierfernandez@ugr.es

12 ORCiD: 0000-0002-5367-1575. Twitter: @javi_fernava

13 Luis Fradua

14 Address: Faculty of Sport Sciences. Carretera de Alfacar s/n 18011, Granada, Spain.

15 Telephone: +34 958244371. Email: fradua @ugr.es

16 Asier Zubillaga

17 Address: Faculty of Sport Sciences, Portal de Lasarte 71, 01007, Vitoria-Gasteiz,

18 Spain. Telephone: +34 945013566. Email: asier.zubillaga@ehu.es

19 Allistair P. McRobert

20 Address: Research Institute for Sport and Exercise Sciences, Liverpool John Moores

21 University, Tom Reilly Building, Liverpool, L3 2ET, UK. Telephone: +44 0151904

22 6258. Email: A.P.McRobert@1jmu.ac.uk

23 Twitter: @allistair1980 


\section{Influence of contextual variables on styles of play in soccer}

The aim of the present study was to evaluate the effect of match status, venue, and quality of opposition on the styles of play in soccer. Data were collected from 380 games of the English Premier League from the 2015-2016 season. Linear mixed models were applied to evaluate the influence of these contextual variables on membership scores for Direct Play, Counterattack, Maintenance, Build Up, Sustained Threat, Fast Tempo, Crossing, and High Pressure. The results showed that match status had a significant effect on the eight styles of play (all $\mathrm{P}<0.001$ ), venue had a significant effect on all styles of play ( $\mathrm{P}<0.01)$ except Counterattack and Maintenance, and quality of opposition had a significant effect on all styles of play $(\mathrm{P}<0.05)$ except Counterattack. Moreover, the interaction between match status and quality of opposition, and venue and quality of opposition showed significant effects on some styles of play. The results of this study imply that contextual variables influence the use of styles of play in soccer match play. Consequently, this provides meaningful recommendations for practitioners in soccer.

Keywords: match analysis; performance analysis; English Premier League; tactics; mixed models

\section{Introduction}

Tactical match analysis represents an important aspect when analysing teams in soccer (Carling, Williams, \& Reilly, 2005; Rein \& Memmert, 2016). Previous studies analysed different attacking and defensive tactical variables in soccer such as ball possession (Bradley, Lago-Peñas, Rey, \& Gomez-Diaz, 2013; da Mota, Thiengo, Gimenes, \& Bradley, 2016; Link \& Hoernig, 2017), ball recovery (Barreira, Garganta, Guimaraes, Machado, \& Anguera, 2014; Liu, Hopkins, \& Gomez, 2016), passing variables (Goncalves et al., 2017; Hughes \& Franks, 2005; Redwood-Brown, 2008; Rein, Raabe, \& Memmert, 2017), shooting variables (Ensum, Pollard, \& 
1 Taylor, 2005; Lago-Peñas, Lago-Ballesteros, Dellal, \& Gomez, 2010), pressure

2 (Link, Lang, \& Seidenschwarz, 2016), set plays (Casal, Maneiro, Arda, Losada, \&

3 Rial, 2014; Casal, Maneiro, Arda, Losada, \& Rial, 2015; Link, Kolbinger, Weber, \&

4 Stockl, 2016), team formation (Bradley et al., 2011; Carling, 2011), and their link to

5 performance in match play. Furthermore, contextual variables (e.g. match play,

6 venue, quality of opposition) influence tactical variables and should be considered

7 when analysing soccer match play (Mackenzie \& Cushion, 2013).

9 behaviour in soccer. For instance, losing teams tend to defend in more advanced

10 zones of the pitch (Almeida, Ferreira, \& Volossovitch, 2014), losing teams increase

11 ball possession compared to winning or drawing teams (Lago, 2009), and losing or

12 drawing teams prefer long passing sequences, whereas winning teams prefer shorter

13 passing sequences (Paixao, Sampaio, Almeida, \& Duarte, 2015). These results

14 provide useful insights about the behaviour of the teams when match status changes.

15 Nevertheless, a more detailed classification of the winning and losing states (i.e.

16 winning or losing by smaller or larger margins) could also provide a better estimation

17 of teams' tactical behaviours (Gomez, Lorenzo, Ibanez, \& Sampaio, 2013).

18 Similarly, researchers have investigated the influence of venue (i.e. playing

19 home or away) on tactical variables during match play. Some of the previous

20 findings showed that away teams regain the ball and place the position of their

21 defensive line closer to their own goal (Santos, Lago-Peñas, \& Garcia-Garcia, 2017),

22 and that has an increase in the total passes played in the defensive pitch third and a

23 decrease in the total of passes played in the attacking pitch third in comparison when

24 playing home (Taylor, Mellalieu, James, \& Barter, 2010). Home advantage is a

25 phenomenon that has been widely studied in soccer (Lago-Peñas, Gomez, \& Pollard, 
1 2017; Pollard, 2006; Pollard \& Gomez, 2009), and is often higher when compared to

2 other sports, such as Baseball, Basketball, Hockey, Rugby or Football (Jamieson,

3 2010). Therefore, venue is an important variable to consider due to its impact on

4 match play performance.

6 Generally, teams with a higher ranking have higher ball possession values compared

7 to lower ranking teams (Bradley, Lago-Peñas, Rey, \& Sampaio, 2014; Lago, 2009).

8 In addition, according to a one team case study, ball recovery location and the

9 defensive line are closer to a team's own goal when the opposition is stronger

10 (Santos et al., 2017). Hence, quality of opposition seemed to affect tactical behaviour

11 in soccer. Moreover, the interaction between venue and quality of opposition shows

12 that teams playing against stronger opposition decrease ball possession compared

13 when playing at home (Lago, 2009). However, previous research examining the

14 influence of opposition quality, venue and match status have often used isolated

15 variables or performance indicators, therefore limiting our understanding of tactical

16 behaviour (Mackenzie \& Cushion, 2013).

17 More recently, styles of play in soccer explain a broader concept of tactical

18 behaviour, where these tactical variables and performance indicators contribute to

19 them. Recent studies proposed a theoretical framework to measure styles of play

20 (Hewitt, Greenham, \& Norton, 2016) and quantified the use of attacking and

21 defensive styles of play in soccer (Fernandez-Navarro, Fradua, Zubillaga, Ford, \&

22 McRobert, 2016). Behaviour indexes (Kempe, Vogelbein, Memmert, \& Nopp,

23 2014), multivariate statistical approaches (Moura, Martins, \& Cunha, 2014), and

24 spatio-temporal analysis (Memmert, Lemmink, \& Sampaio, 2017) have also been

25 used to identify tactics and potentially identify styles of play. A previous study 
1 examined the influence of match location on possession types in soccer considered as

\section{Methods}

\section{Match sample}

12 Match data from all 380 games of the 2015-2016 English Premier League (EPL)

13 season were included in the study. There were 38 games for each of the 20 teams

14 participating in the league, so an equal number of matches for every team was

15 available. Data were obtained from a valid and reliable computerised multiple

16 camera match analysis tracking system (STATS LLC, Chicago, IL, USA) (Bradley,

17 O'Donoghue, Wooster, \& Tordoff, 2007; Di Salvo, Collins, McNeill, \& Cardinale,

18 2006). The present study was approved by the Human Research Ethics Committee of

19 the University of Granada.

\section{Procedure}

21 A total of 380 individual games files containing all team possessions $(\mathrm{N}=$

22 94966) for the season were merged into a single file using KNIME Analytics

23 Platform (KNIME GmbH, Konstanz, Germany). Each possession was allocated a 
1 percentage membership score for the 8 styles of play defined by STATS (Table 1).

2 Each possession is given a value from 0 to 1 for each of the styles and any possession

3 can score on multiple styles. For instance, a team possession could involve the use of

4 Build Up (.8), Sustained Threat (.5), and Fast Tempo(.25) styles (Ruiz, 2016). Set

5 plays were removed from the dataset as no clear styles occur during these actions.

6 Possessions with values of 0 for every style were also removed as they represented

7 quick turnovers of possession (e.g. a tackle, turnover possession followed by another

8 tackle and turnover or an interception), leaving a total of 68766 possessions for

9 analysis. The contextual variables match status, venue, and quality of opposition

10 were also recorded for each possession. The five match status categories were losing

11 by two goals or more, losing by one goal, drawing, winning by one goal, and

12 winning by two goals or more. Most of the previous studies have only focused on

13 analysing winning, drawing or losing in match status (Lago, 2009; Santos et al.,

14 2017; Vogelbein, Nopp, \& Hokelmann, 2014). In contrast, other research considered

15 each possible scoreline occurring when analysing team performance (Redwood-

16 Brown, 2008). We believe that distinctions between these losing and winning status

17 based on the number of goals should be made because one goal

18 advantages/disadvantages could influence the styles of play differently compared to

19 two or more goals advantages/disadvantages (e.g. with a two goals advantage,

20 receiving one goal will not change the wining status, however with a one goal

21 advantage, receiving one goal will change the match status to drawing). Venue was

22 categorised as playing home or away, whereas quality of opposition was measured

23 according to the difference in the teams ranking position at the end of the season

24 (Lago-Peñas, Gomez-Ruano, Megias-Navarro, \& Pollard, 2016; Lago-Peñas et al.,

25 2017). Therefore, a positive value in this ranking difference indicates facing a strong 
1 opposition and, on the other hand, a negative value represents facing a weak

2 opposition. The highest the absolute value of this ranking difference the stronger or

3 weaker opposition is faced (e.g. a ranking difference of +14 shows that the team is

4 facing an opposition team that is 14 positions above in the ranking).

[Table 1 near here]

\section{$8 \quad$ Statistical analysis}

9 A linear mixed model (LMM) was carried out for each of the eight styles using the

10 MIXED procedure of the software SPSS v.23.0 for Windows (IBM, Armonk, NY

11 USA). LMM organises data into a hierarchical structure by creating nesting units.

12 For example, ball possessions are nested into matches. Ball possessions and matches

13 represent two different levels were matches are higher in the hierarchy than ball

14 possessions. In addition, model complexity can increase when more levels are added.

15 For example, balls possessions can be nested into matches, and these matches can

16 also be nested into teams. This represents a 3 levels structure being the unit team the

17 higher in the hierarchy. A cross-classified multilevel design (Heck, Thomas, \&

18 Tabata, 2014) was developed considering matches and teams as the nesting levels.

19 Therefore, the variables match and team were considered as random effects. The

20 cross-classified multilevel models are suitable for data structures that are not purely

21 hierarchical. In other words, data structures where units in one level are not nested

22 only in a higher level. For example, matches are nested in two different teams as

23 there are two teams participating in the game. Match status, venue, and quality of

24 opposition (i.e. ranking difference) were considered as fixed effects in the models. In 
1 addition, random slopes of these fixed effects and interactions between them were

2 also checked to verify if they had a significant contribution to each model. We

3 applied a general multilevel-modelling strategy (Heck et al., 2014) where we

4 included fixed and random effects in different steps from the simplest to the most

5 complex. The simplest model and the first one to apply was a 'Null' model were only

6 the dependent variable (i.e. the style of play) in the hierarchy structure is modelled.

7 No predictors (i.e. match status, venue, and quality of opposition) are added into this

8 model. Later, the individual level random intercept is developed to examine the

9 effect of the predictors at the individual level. Then, a group level random intercept

10 model is developed including the predictors of the individual level. This model

11 allows us to evaluate the effect of the other predictors on the dependent variable.

12 Next, random slopes of the predictors are added in a following model to check if

13 these variables randomly vary across units. In case any significant results are found

14 when running the models with predictors with random slopes, interactions should be

15 checked in following models to evaluate if they explain the variability in the random

16 slopes. Model comparison for each step was done using the Akaike information

17 criterion (AIC) (Akaike, 1973) where a lower value represented a better model, and a

18 chi-square likelihood ratio test (Field, 2013). In other words, models were compared

19 by subtracting the log-likelihood of the new model from the value of the old one and

20 considering the degrees of freedom equal to the difference in the number of

21 parameters between the two models. Besides de AIC, a lower value of the chi-square

22 log-likelihood test represented a better model and showed if the changes were

23 significant. These comparisons were done between each model according to the steps

24 described above. After adding an additional predictor, random slope, or interaction,

25 model comparison was performed to assess the improvement in the new model. Final 
1 models presented in Table 2 were chosen according to better values of AIC, log-

2 likelihood, and significant effect of variables. We used maximum likelihood (ML)

3 estimation for model comparison and for the final model of each style of play we

4 refitted the best model again using restricted maximum likelihood (REML)

5 estimation. ML estimation was employed for model comparison as chi-square

6 likelihood ratio tests requires this type of estimation (Field, 2013; Heck et al., 2014).

7 We reported marginal and conditional $R^{2}$ metrics (Nakagawa \& Schielzeth, 2013) for

8 each LMM to provide some measure of effect-sizes. The level of significance was set

9 to 0.05 .

\section{Results}

11 The effects of match status, venue and quality of opposition on each of the eight

12 styles of play employed by teams are shown in Table 2.

[Table 2 near here]

\section{Match status}

17 Compared to drawing, teams losing had a decrease in Direct Play $(\mathrm{P}<0.001$ for

18 losing by one and losing by two or more goals) and Maintenance $(\mathrm{P}<0.001)$, and an

19 increase in Build Up (P $<0.001$ for losing by one and losing by two or more goals),

20 Sustained Threat ( $\mathrm{P}<0.001$ for losing by one and losing by two or more goals), and

21 Crossing ( $\mathrm{P}<0.001$ for losing by one and losing by two or more goals). In addition,

22 an increase in Fast Tempo $(\mathrm{P}<0.05)$ was observed when teams were losing by two

23 or more goals. In contrast, there were decreases in Maintenance $(\mathrm{P}<0.001$ for

24 wining by one and wining by two or more goals), Build $\mathrm{Up}(\mathrm{P}<0.001$ and $\mathrm{P}<0.05$ 
1 for wining by one and wining by two or more goals respectively), Sustained Threat

$2 \quad$ ( $\mathrm{P}<0.001$ and $\mathrm{P}<0.01$ for wining by one and wining by two or more goals

3 respectively), Crossing ( $\mathrm{P}<0.001$ for wining by one and wining by two or more

4 goals $)$ and High Pressure $(\mathrm{P}<0.001$ and $\mathrm{P}<0.01$ for wining by one and wining by

5 two or more goals respectively), and an increase in Direct Play $(\mathrm{P}<0.001$ for wining

6 by one and wining by two or more goals), Counterattack $(\mathrm{P}<0.001$ for wining by

7 one and wining by two or more goals $)$ and Fast Tempo $(\mathrm{P}<0.001)$ for teams wining

8 by two or more goals.

9 There was an interaction between match status and quality of opposition for

10 Direct Play, Maintenance, and High Pressure styles. Direct Play decreased more

11 when teams faced stronger opposition and were losing by one, or by two or more

12 goals $(\mathrm{P}<0.01$ and $\mathrm{P}<0.05$ respectively $)$. Maintenance increased when losing by

13 one, or by two or more goals when facing stronger opposition $(\mathrm{P}<0.05)$. In contrast,

14 maintenance decreased when winning by two or more goals $(\mathrm{P}<0.001)$ against

15 stronger opponents. High Pressure decreased when teams were winning by two or

16 more goals against stronger opponents $(\mathrm{P}<0.01)$.

\section{Venue}

18 Away teams increased Direct Play $(\mathrm{P}<0.001)$ and decreased Build Up $(\mathrm{P}<0.001)$,

19 Sustained Threat $(\mathrm{P}<0.001)$, Fast Tempo $(\mathrm{P}<0.01)$, Crossing $(\mathrm{P}<0.001)$ and High

20 Pressure $(\mathrm{P}<0.001)$, in comparison to home teams. A significant interaction

21 between venue and quality of opposition was observed for Build Up. Away teams

22 decreased Build Up $(\mathrm{P}<0.05)$ when facing stronger opponents.

\section{Quality of opposition}

24 There was an increase in Direct Play $(\mathrm{P}<0.001)$, and decrease in Maintenance $(\mathrm{P}<$ 
1 0.01), Build Up $(\mathrm{P}<0.001)$, Sustained Threat $(\mathrm{P}<0.001)$, Fast Tempo $(\mathrm{P}<0.001)$,

2 Crossing $(\mathrm{P}<0.001)$ and High Pressure $(\mathrm{P}<0.05)$ against stronger opposition.

\section{Discussion}

5 The aim of the present study was to examine the effect of match status, venue, and

6 quality of opposition on different styles of play in soccer. The findings suggest that

7 these contextual variables influence styles of play and should be considered when

8 reviewing match play. However, these effects showed a small effect size on the

9 styles of play measured. As some styles were infrequent, low values for these styles

10 of play were shown in the normative profiles. Nevertheless, significant results

11 showed that contextual variables produced a change in the average use of a style of

12 play, even if it appeared as a low value. Mixed models also showed that these

13 normative profiles could change across matches and teams, therefore teams

14 demonstrated different tactical behaviours under different contexts. To our

15 knowledge, this is the first study investigating the effect of contextual variables on

16 styles of play used by teams in soccer.

17 Match status had a significant effect on the eight styles of play measured. For

18 instance, losing teams decreased their use of direct play and increased build up and

19 sustained threat. Whereas, winning teams increased their use of direct play and

20 counterattack, and decreased the use of maintenance, build up, and sustained threat.

21 Maintenance, build up and sustained threat are associated with ball possession,

22 therefore teams who prefer a possession-based approach score higher on these styles.

23 A possible explanation for winning teams reduction in these styles could be a focus

24 on maintaining the advantage through defending, which results in reduced possession 
1 time (Jones, James, \& Mellalieu, 2004; Redwood-Brown, 2008). Moreover, this

2 could also explain their increase in the use of direct play and counterattack when

3 winning as these styles allow the team to keep players close to the own goal and

4 taking advantage of the advanced position of opposing teams to try to score. On the

5 other hand, teams losing decreased the use of direct play and increased the use of

6 build up and sustained threat to try maintain the attack close to the oppositions goal.

7 In addition, the retreat of the opposition team close to their goal could also cause this

8 behaviour. These results are in line with previous studies that showed that ball

9 possession by teams increased when losing and decreased when winning and

10 drawing (Bradley et al., 2014; Jones et al., 2004; Lago, 2009; Lago \& Martin, 2007)

11 and that winning teams can take advantage of direct play and counterattack (Garcia-

12 Rubio, Gomez, Lago-Peñas, \& Ibanez, 2015).

13 Fast tempo style of play was affected in the extreme cases of match status

14 (i.e. winning or losing by two or more goals). Teams winning or losing by a high

15 margin of goals increased the use of fast tempo compared to a drawing status. The

16 findings by Wallace and Norton (2014) showed that fast ball movement, generated

17 by a combination of high passing rates and high ball speed, were advantageous in

18 soccer. Therefore, teams losing by two or more goals could employ this style of play

19 to create space in the opposing half and achieve a goal as soon as possible to allow

20 them more possibilities of obtaining draw or win the game. In contrast, teams

21 winning by a margin of two or more goals increased the use of this style possibly as a

22 tactic to avoid intense pressure from the opposing team that is in a hurry to regain the

23 ball and score as soon as possible. Furthermore, crossing decreased when winning

24 and increased when losing. Previous research (Casamichana, Castellano, Calleja-

25 Gonzalez, \& San Roman, 2013; Liu, Gomez, Lago-Peñas, \& Sampaio, 2015) 
1 reported that crosses were more frequent for losing teams, which might suggest that

2 losing teams employ this tactic to create more goal scoring opportunities when

3 attacking. The use of high pressure by winning teams decreased. This could help the

4 team 'save' energy in the game as they do not need to make efforts to equalise the

5 game. Interaction between match status and quality of opposition showed significant

6 differences for direct play, maintenance and high pressure. Firstly, losing teams

7 showed a decrease in the use of direct play and an increase in the use of maintenance

8 when facing a stronger opposition, and showed a decrease in maintenance when

9 winning and facing strong opposition. This could be explained by a strong reaction

10 of the losing teams to try dominate possession against better opponents. Secondly,

11 when teams were winning by two or more goals, the use of high pressure decreased

12 when facing strong opposition. The strategy of these teams could be to maintain the

13 scoreline and prevent the other team from scoring by employing a defence close to

14 their own goal.

15 Venue showed a significant effect for all styles of play except counterattack

16 and maintenance. According to previous research, ball possession increased for home

17 teams (Lago-Peñas \& Dellal, 2010; Lago, 2009; Lago \& Martin, 2007). Our data

18 supports this previously reported increase in possession for home teams, but more

19 specifically that this is a result of increased possession during build up and sustained

20 threat and a reduction in direct play. Therefore, home teams dominate possession in

21 more attacking areas (i.e. attacking third) compared to away teams (Lago, 2009).

22 Consequently, these results support home advantage phenomena in soccer and other

23 sports. Although this aspect has been widely studied, the reasons for it are not clear

24 (Carron, Loughhead, \& Bray, 2005). Crowd support seems to be a major factor

25 (Nevill \& Holder, 1999), however, referee bias, psychological factors, familiarity 
1 with the pitch and travel effects seems to be also some of the possible explanations

2 (Pollard \& Pollard, 2005). In addition, the use of fast tempo, crossing, and high

3 pressure were higher when playing home in comparison when playing away. These

4 styles of play suggest aggressive play that aims to get as many scoring opportunities

5 as possible and seems to be a team behaviour when the team is playing home (Lago-

6 Peñas et al., 2017). Regaining ball possession in advanced zones of the pitch as a

7 consequence of high pressure strategies is linked to success (Almeida et al., 2014),

8 similarly as fast ball movement (Wallace \& Norton, 2014). Therefore, this fact could

9 explain this aggressive behaviour by home teams. An interaction between venue and

10 quality of opposition was significant for build up. Teams playing away tend to

11 decrease their use of build up when facing strong opposition. This could be because

12 the stronger team at home team would further dominate ball possession and increase

13 the home advantage effect.

14 Moreover, quality of opposition demonstrated an effect on all the styles of

15 play except counterattack. Previous research observed that facing a strong opposition

16 was associated with a decrease of ball possession (Lago-Peñas, Lago-Ballesteros, \&

17 Rey, 2011; Lago, 2009). The present study also showed that the direct play

18 increased, whereas maintenance, build up, and sustained threat decreased when

19 facing a stronger opposition. This suggests that weaker teams maintain players closer

20 to their own goal and employ direct play, while stronger teams tend to dominate

21 using possession-based styles. The use of fast tempo decreased when facing a strong

22 opposition. As this style of play requires good passing and dribbling abilities of

23 players, it is expected that better teams have better players that are able to develop

24 fast tempo in their ball possessions. In addition, results showed that the use of

25 crossing was significantly higher when playing against weak opposition. Previous 
1 research indicated contradictory conclusions, showing that losing teams had higher

2 averages for crosses (Lago-Peñas et al., 2010). Difference in crosses might be due

3 different tactical behaviours between the Spanish League and English Premier

4 League. Results of the present study also showed that the use of high pressure

5 increased when facing a weaker opposition. This is in accordance with previous

6 research showing that better ranked teams in the UEFA Champions League were

7 more effective in applying high pressure (Almeida et al., 2014) and that facing a

8 strong opposition made teams regain the ball and locate their defensive line closer to

9 their own goal (Santos et al., 2017). Better teams could feel more confident

10 defending next to the opposite goals, mainly because better players playing in these

11 teams can perform this pressure successfully.

12 The current study uses a large data set from a full season, however data

13 corresponded to a single league. Consequently, generalisation to other leagues and

14 seasons is limited and should be considered with caution (Mackenzie \& Cushion,

15 2013). As previous research showed with ball possession (Collet, 2013), it is possible

16 that effects of contextual variables on styles of play employed by teams could be

17 diminished in different contexts (e.g. non domestic leagues). In addition, the styles of

18 play defined in this study are a proposal for styles of play in soccer. Maybe other

19 researchers and practitioners could consider different ways to define the same styles

20 of play described in this study or even consider different ones. However, the

21 approach employed in this study is generally in accordance with previous research

22 and practitioners' points of view. Moreover, event data was used for this study and

23 the use of spatio-temporal data could provide a more insightful analysis of team

24 behaviour (Link, Lang, et al., 2016; Memmert et al., 2017). As a consequence of the

25 previous reasons, caution is needed when interpreting the present findings. Future 
1 research should extend the investigation to other leagues and seasons to account for

2 more different situations. The results of this study and the approach employed could

3 be used by coaches, performance analysts, and other practitioners in practice.

4 Knowing the behaviour of teams under specific contextual variables will prepare

5 teams to react to their opponents and improve their tactics on training. Similar

6 models could be applied to evaluate the influence of contextual variables on other

7 leagues and teams.

\section{Conclusions}

10 This study showed that match status, venue, and quality of opposition influence the

11 use of styles of play in soccer match play. The use of mixed models is useful to

12 evaluate these situations under a multilevel approach, suitable for soccer. Models

13 show in detail how these contextual variables affect the eight styles of play

14 considered in the study (Direct Play, Counterattack, Maintenance, Build Up,

15 Sustained Threat, Fast Tempo, Crossing, and High Pressure). Consequently,

16 contextual variables should be accounted for when analysing styles of play in soccer.

\section{Funding}

18 This study was supported by the Spanish Ministry of Education under Grant

19 [FPU13/05369].

\section{Acknowledgements}

21 The authors would like to thank STATS for providing access to the data used in this

22 research. This study is part of the PhD thesis of Javier Fernandez-Navarro for the

23 Biomedicine programme of the University of Granada, Spain. 


\section{References}

2 Akaike, H. (1973). Information Theory and an Extension of the Maximum Likelihood Principle. Paper presented at the Second International Symposium on Information Theory, Budapest.

Almeida, C. H., Ferreira, A. P., \& Volossovitch, A. (2014). Effects of Match Location, Match Status and Quality of Opposition on Regaining Possession in UEFA Champions League. Journal of Human Kinetics, 41(1), 203-214.

Barreira, D., Garganta, J., Guimaraes, P., Machado, J., \& Anguera, M. T. (2014). Ball recovery patterns as a performance indicator in elite soccer. Proceedings of the Institution of Mechanical Engineers Part P-Journal of Sports Engineering and Technology, 228(1), 61-72.

Bradley, P., O'Donoghue, P., Wooster, B., \& Tordoff, P. (2007). The reliability of ProZone MatchViewer: a video-based technical performance analysis system. International Journal of Performance Analysis in Sport, 7(3), 117-129.

Bradley, P. S., Carling, C., Archer, D., Roberts, J., Dodds, A., Di Mascio, M., . . . Krustrup, P. (2011). The effect of playing formation on high-intensity running and technical profiles in English FA Premier League soccer matches. Journal of Sports Sciences, 29(8), 821-830.

Bradley, P. S., Lago-Peñas, C., Rey, E., \& Gomez-Diaz, A. (2013). The effect of high and low percentage ball possession on physical and technical profiles in English FA Premier League soccer matches. Journal of Sports Sciences, 31(12), 1261-1270.

Bradley, P. S., Lago-Peñas, C., Rey, E., \& Sampaio, J. (2014). The influence of situational variables on ball possession in the English Premier League. Journal of Sports Sciences, 32(20), 1867-1873.

Carling, C. (2011). Influence of opposition team formation on physical and skillrelated performance in a professional soccer team. European Journal of Sport Science, 11(3), 155-164.

Carling, C., Williams, A. M., \& Reilly, T. (2005). Handbook of Soccer Match Analysis. A Systematic Approach to Improving Performance. London: Routledge. 
1 Carron, A. V., Loughhead, T. M., \& Bray, S. R. (2005). The home advantage in sport competitions: Courneya and Carron's (1992) conceptual framework a decade later. Journal of Sports Sciences, 23(4), 395-407.

4 Casal, C. A., Maneiro, R., Arda, T., Losada, J. L., \& Rial, A. (2014). Effectiveness of Indirect Free Kicks in Elite Soccer. International Journal of Performance Analysis in Sport, 14(3), 744-760.

7 Casal, C. A., Maneiro, R., Arda, T., Losada, J. L., \& Rial, A. (2015). Analysis of Corner Kick Success in Elite Football. International Journal of Performance Analysis in Sport, 15(2), 430-451.

Casamichana, D., Castellano, J., Calleja-Gonzalez, J., \& San Roman, J. (2013). Differences between winning, drawing and losing teams in the 2010 World Cup. In H. Nunome, B. Drust \& B. Dawson (Eds.), Science and Football VII (pp. 211-216). London: Routledge.

Collet, C. (2013). The possession game? A comparative analysis of ball retention and team success in European and international football, 2007-2010. Journal of Sports Sciences, 31(2), 123-136.

da Mota, G. R., Thiengo, C. R., Gimenes, S. V., \& Bradley, P. S. (2016). The effects of ball possession status on physical and technical indicators during the 2014 FIFA World Cup Finals. Journal of Sports Sciences, 34(6), 493-500.

Di Salvo, V., Collins, A., McNeill, B., \& Cardinale, M. (2006). Validation of Prozone : A new video-based performance analysis system. International Journal of Performance Analysis in Sport, 6(1), 108-119.

Ensum, J., Pollard, R., \& Taylor, S. (2005). Applications of Logistic Regression to Shots at Goal in Association Football. In T. Reilly, J. Cabri \& D. Araujo (Eds.), Science and Football V (pp. 211-218). London: Routledge.

Fernandez-Navarro, J., Fradua, L., Zubillaga, A., Ford, P. R., \& McRobert, A. P. (2016). Attacking and defensive styles of play in soccer: analysis of Spanish and English elite teams. Journal of Sports Sciences, 34(24), 2195-2204.

Field, A. (2013). Discovering Statistics Using IBM SPSS Statistics (4th ed.). London: SAGE Publications.

Garcia-Rubio, J., Gomez, M. A., Lago-Peñas, C., \& Ibanez, S. J. (2015). Effect of match venue, scoring first and quality of opposition on match outcome in the 
UEFA Champions League. International Journal of Performance Analysis in Sport, 15(2), 527-539.

3 Gomez, M. A., Lorenzo, A., Ibanez, S. J., \& Sampaio, J. (2013). Ball possession effectiveness in men's and women's elite basketball according to situational variables in different game periods. Journal of Sports Sciences, 31(14), 15781587.

7 Goncalves, B., Coutinho, D., Santos, S., Lago-Peñas, C., Jimenez, S., \& Sampaio, J. (2017). Exploring Team Passing Networks and Player Movement Dynamics in Youth Association Football. Plos One, 12(1), 13.

Heck, R. H., Thomas, S. L., \& Tabata, L. N. (2014). Multilevel and Longitudinal Modeling with IBM SPSS (2nd ed.). New York, NY: Routledge (Taylor \& Francis Group).

Hewitt, A., Greenham, G., \& Norton, K. (2016). Game style in soccer: what is it and can we quantify it? International Journal of Performance Analysis in Sport, 16(1), 355-372.

Hughes, M., \& Franks, I. (2005). Analysis of passing sequences, shots and goals in soccer. Journal of Sports Sciences, 23(5), 509-514.

Jamieson, J. P. (2010). The Home Field Advantage in Athletics: A Meta-Analysis. Journal of Applied Social Psychology, 40(7), 1819-1848.

Jones, P. D., James, N., \& Mellalieu, S. D. (2004). Possession as a performance indicator in soccer. International Journal of Performance Analysis in Sport, 4(1), 98-102.

Kempe, M., Vogelbein, M., Memmert, D., \& Nopp, S. (2014). Possession vs. Direct Play: Evaluating Tactical Behavior in Elite Soccer. International Journal of Sports Science, 4(6A), 35-41.

Lago-Peñas, C., \& Dellal, A. (2010). Ball Possession Strategies in Elite Soccer According to the Evolution of the Match-Score: the Influence of Situational Variables. Journal of Human Kinetics, 25, 93-100. 
Lago-Peñas, C., Gomez, M. A., \& Pollard, R. (2017). Home advantage in elite soccer matches. A transient effect? International Journal of Performance Analysis in Sport, 17(1-2), 86-95.

4 Lago-Peñas, C., Lago-Ballesteros, J., Dellal, A., \& Gomez, M. (2010). Game-related statistics that discriminated winning, drawing and losing teams from the Spanish soccer league. Journal of Sports Science and Medicine, 9(2), 288293.

Lago-Peñas, C., Lago-Ballesteros, J., \& Rey, E. (2011). Differences in Performance Indicators between Winning and Losing Teams in the UEFA Champions League. Journal of Human Kinetics, 27, 137-148.

Lago, C. (2009). The influence of match location, quality of opposition, and match status on possession strategies in professional association football. Journal of Sports Sciences, 27(13), 1463-1469.

Lago, C., \& Martin, R. (2007). Determinants of possession of the ball in soccer. Journal of Sports Sciences, 25(9), 969-974.

Link, D., \& Hoernig, M. (2017). Individual ball possession in soccer. Plos One, 12(7), 15 .

Link, D., Kolbinger, O., Weber, H., \& Stockl, M. (2016). A topography of free kicks in soccer. Journal of Sports Sciences, 34(24), 2312-2320.

Link, D., Lang, S., \& Seidenschwarz, P. (2016). Real Time Quantification of Dangerousity in Football Using Spatiotemporal Tracking Data. Plos One, 11(12), 16.

Liu, H., Gomez, M. A., Lago-Peñas, C., \& Sampaio, J. (2015). Match statistics related to winning in the group stage of 2014 Brazil FIFA World Cup. Journal of Sports Sciences, 33(12), 1205-1213.

Liu, H., Hopkins, W. G., \& Gomez, M. A. (2016). Modelling relationships between match events and match outcome in elite football. European Journal of Sport Science, 16(5), 516-525.

Mackenzie, R., \& Cushion, C. (2013). Performance analysis in football: A critical review and implications for future research. Journal of Sports Sciences, 31(6), 639-676. 
1 Memmert, D., Lemmink, K. A. P. M., \& Sampaio, J. (2017). Current Approaches to Tactical Performance Analyses in Soccer Using Position Data. Sports Medicine, 47(1), 1-10.

4 Moura, F. A., Martins, L. E. B., \& Cunha, S. A. (2014). Analysis of football gamerelated statistics using multivariate techniques. Journal of Sports Sciences, 32(20), 1881-1887.

Nakagawa, S., \& Schielzeth, H. (2013). A general and simple method for obtaining R2 from generalized linear mixed-effects models. Methods in Ecology and Evolution, 4(2), 133-142.

Nevill, A. M., \& Holder, R. L. (1999). Home advantage in sport - An overview of studies on the advantage of playing at home. Sports Medicine, 28(4), 221236.

Paixao, P., Sampaio, J., Almeida, C. H., \& Duarte, R. (2015). How does match status affects the passing sequences of top-level European soccer teams? International Journal of Performance Analysis in Sport, 15(1), 229-240.

Pollard, R. (2006). Worldwide regional variations in home advantage in association football. Journal of Sports Sciences, 24(3), 231-240.

Pollard, R., \& Gomez, M. A. (2009). Home advantage in football in South-West Europe: Long-term trends, regional variation, and team differences. European Journal of Sport Science, 9(6), 341-352.

Pollard, R., \& Pollard, G. (2005). Home advantage in soccer. A review of its existence and causes. International Journal of Soccer and Science, 3(1), 2838.

Redwood-Brown, A. (2008). Passing patterns before and after goal scoring in FA Premier League Soccer. International Journal of Performance Analysis in Sport, 8(3), 172-182.

Rein, R., \& Memmert, D. (2016). Big data and tactical analysis in elite soccer: future challenges and opportunities for sports science. Springerplus, 5, 13.

Rein, R., Raabe, D., \& Memmert, D. (2017). "Which pass is better?" Novel approaches to assess passing effectiveness in elite soccer. Human Movement Science, 55, 172-181.

Ruiz, H. (2016, January 27). Advanced Analytics in Soccer/Football: Playing Styles Analysis [Webinar]. In STATS. Retrieved from 
3 Santos, P., Lago-Peñas, C., \& Garcia-Garcia, O. (2017). The influence of situational variables on defensive positioning in professional soccer. International Journal of Performance Analysis in Sport, 17(3), 212-219.

6 Taylor, J. B., Mellalieu, S. D., James, N., \& Barter, P. (2010). Situation variable effects and tactical performance in professional association football. International Journal of Performance Analysis in Sport, 10(3), 255-269.

9 Tenga, A. P. C., Holme, I., Ronglan, L. T., \& Bahr, R. (2010). Effects of Match Location on Playing Tactics for Goal Scoring in Norwegian Professional Soccer. Journal of Sport Behavior, 33(1), 89-108.

Vogelbein, M., Nopp, S., \& Hokelmann, A. (2014). Defensive transition in soccer are prompt possession regains a measure of success? A quantitative analysis of German Fussball-Bundesliga 2010/2011. Journal of Sports Sciences, 32(11), 1076-1083. 


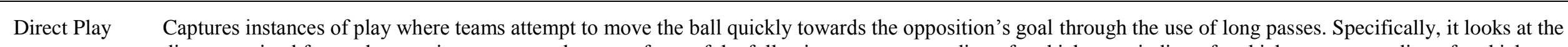
distance gained forward every time a team makes use of any of the following events: pass, direct free kick pass, indirect free kick pass, cross, direct free kick cross, indirect free kick cross, goal kick, goalkeeper throw, goalkeeper kick, throw in, or clearance. The forward distance gained must be greater than 20 metres and reaches $100 \%$ at 40 metres.

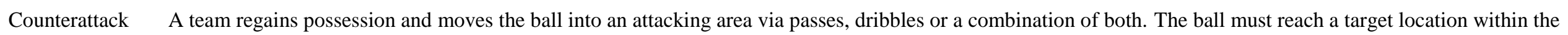
opposition's half. This location varies depending on the regain location. The speed of the transition from a regain to a target location determines the Counter Attack value. The quicker the ball is moved up the pitch, the higher the Counter Attack value. Counter attack regains include: goal keeper catch, goal keeper save, interception, clearance, header, tackle and block. Counter Attack distance gained include: touch, dribbling, clearance and pass.

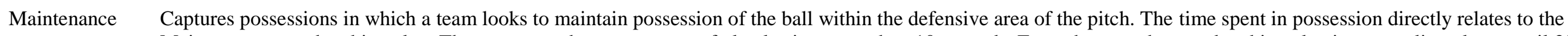
Maintenance membership value. The team must have a passage of play lasting more than 10 seconds. From then on, the membership value increases linearly up until 30 seconds where it reaches $100 \%$.

Build Up Captures long and controlled ball possessions - but is aimed at periods of play where a team is looking for opportunities to attack. The calculation is similar to Maintenance with the differences being the zone on the pitch and the time thresholds. The Build Up area is between the halfway line and the opposition's penalty area and the passage of play must last more than 8 seconds. From then on, the membership value increases linearly up until 25 seconds where it reaches $100 \%$.

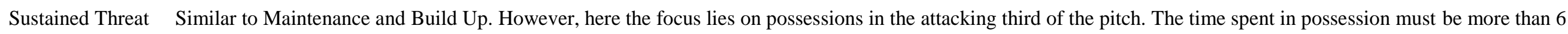
seconds, reaching $100 \%$ at 20 seconds.

Fast Tempo Captures when the team is moving the ball quickly to increase the tempo and speed of the game. Fast Tempo looks at sequences of consecutive individual 'fast possessions'. An individual fast possession must occur in the opposition's half and can be achieved as follows: the player releases the ball to a team mate in less than 2 seconds, or the player dribbles at a high tempo.

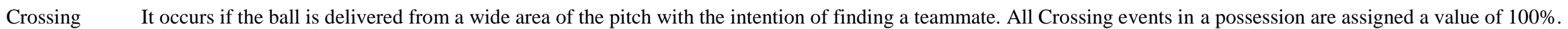
The value assigned to the team possession can only be $0 \%$ or $100 \%$ depending on the occurrence of a crossing event. Crossing events are: cross, corner cross, direct free kick cross and indirect free kick cross.

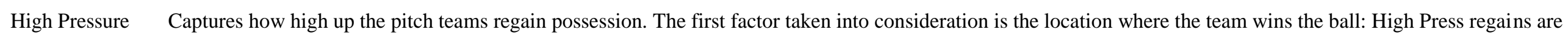
those higher than 5 metres prior to the halfway line. The value increases linearly up until 15 metres into the opposition's half where it reaches $100 \%$. The second factor is the opposition's time in possession prior to the High Press regain happening. To retain the full value established based on the regain location, the opposition must have been in possession for at least 10 seconds. This time factor is introduced to try and capture controlled pressing efforts rather than 'counter press' regains. The combination of these two factors leads to the final High Press membership value. Regain events include: interception, header, tackle and block. 
Table 2. Effects of match status, venue and quality of opposition on each of the 8 styles of play measured in the 2015-2016 English Premier League

\begin{tabular}{|c|c|c|c|c|c|c|c|c|c|c|c|c|}
\hline \multirow[b]{2}{*}{ Fixed effects } & \multicolumn{3}{|c|}{ Direct Play } & \multicolumn{3}{|c|}{ Counterattack } & \multicolumn{3}{|c|}{ Maintenance } & \multicolumn{3}{|c|}{ Build Up } \\
\hline & $\beta$ & $95 \% \mathrm{CI}$ & $P$ & $\beta$ & $95 \% \mathrm{CI}$ & $P$ & $\beta$ & $95 \% \mathrm{CI}$ & $P$ & $\beta$ & $95 \% \mathrm{CI}$ & $P$ \\
\hline Intercept & 0.396 & $0.365,0.427$ & $<0.001$ & 0.048 & $0.044,0.052$ & $<0.001$ & 0.135 & $0.122,0.148$ & $<0.001$ & 0.096 & $0.083,0.109$ & $<0.001$ \\
\hline Match status ( -2 or more) & -0.075 & $-0.097,-0.052$ & $<0.001$ & -0.004 & $-0.009,0.001$ & 0.098 & -0.009 & $-0.019,0.001$ & 0.080 & 0.035 & $0.025,0.046$ & $<0.001$ \\
\hline Match status (-1) & -0.052 & $-0.071,-0.034$ & $<0.001$ & -0.003 & $-0.007,0.001$ & 0.100 & -0.013 & $-0.019,-0.006$ & $<0.001$ & 0.025 & $0.017,0.034$ & $<0.001$ \\
\hline Match status (+1) & 0.075 & $0.057,0.094$ & $<0.001$ & 0.014 & $0.010,0.017$ & $<0.001$ & -0.022 & $-0.029,-0.016$ & $<0.001$ & -0.018 & $-0.027,-0.009$ & $<0.001$ \\
\hline Match status ( +2 or more) & 0.070 & $0.047,0.093$ & $<0.001$ & 0.018 & $0.013,0.023$ & $<0.001$ & -0.024 & $-0.034,-0.014$ & $<0.001$ & -0.013 & $-0.024,-0.002$ & 0.021 \\
\hline Venue (away) & 0.057 & $0.048,0.067$ & $<0.001$ & - & - & - & - & - & - & -0.012 & $-0.016,-0.007$ & $<0.001$ \\
\hline Quality opposition & 0.003 & $0.002,0.005$ & $<0.001$ & - & - & - & -0.001 & $-0.001,-<0.001$ & 0.004 & -0.002 & $-0.003,-0.002$ & $<0.001$ \\
\hline Match status (-2 or more) * Quality opposition & -0.003 & $-0.005,-<0.001$ & 0.022 & - & - & - & 0.001 & $<0.001,0.003$ & 0.015 & - & - & - \\
\hline Match status $(-1) *$ Quality opposition & -0.002 & $-0.004,-0.001$ & 0.003 & - & - & - & 0.001 & $<0.001,0.002$ & 0.013 & - & - & - \\
\hline Match status $(+1) *$ Quality opposition & 0.001 & $-0.001,0.002$ & 0.498 & - & - & - & $-<0.001$ & $-0.001,0.001$ & 0.710 & - & - & - \\
\hline Match status $(+2$ or more) $*$ Quality opposition & 0.001 & $-0.001,0.003$ & 0.401 & - & - & - & -0.002 & $-0.003,-0.001$ & 0.001 & - & - & - \\
\hline Venue (away) * Quality opposition & - & - & - & - & - & - & - & - & - & -0.001 & $<0.001,0.002$ & 0.019 \\
\hline Random effects & $\beta$ & $95 \% \mathrm{CI}$ & $P$ & $\beta$ & $95 \% \mathrm{CI}$ & $P$ & $\beta$ & $95 \% \mathrm{CI}$ & $P$ & $\beta$ & $95 \% \mathrm{CI}$ & $P$ \\
\hline Match & $<0.001$ & $<0.001,0.001$ & 0.009 & $<0.001$ & $<0.001,<0.001$ & 0.008 & 0.001 & $0.001,0.001$ & $<0.001$ & $<0.001$ & $<0.001,0.001$ & $<0.001$ \\
\hline Match status & 0.001 & $0.001,0.002$ & $<0.001$ & - & - & - & $<0.001$ & $<0.001,0.001$ & $<0.001$ & $<0.001$ & $<0.001,0.001$ & $<0.001$ \\
\hline Quality opposition & $<0.0001$ & $<0.001,<0.001$ & $<0.001$ & - & - & - & - & - & - & $<0.001$ & $<0.001,<0.001$ & $<0.001$ \\
\hline Team & 0.004 & $0.002,0.007$ & 0.004 & $<0.001$ & $<0.001,<0.001$ & 0.008 & 0.001 & $<0.001,0.001$ & 0.003 & 0.001 & $<0.001,0.001$ & 0.005 \\
\hline Match status & $<0.001$ & $<0.001,0.001$ & 0.006 & - & - & - & - & - & - & $<0.001$ & $<0.001,<0.001$ & 0.020 \\
\hline Residuals & 0.177 & $0.175,0.179$ & $<0.001$ & 0.028 & $0.028,0.028$ & $<0.001$ & 0.058 & $0.058,0.059$ & $<0.001$ & 0.047 & $0.046,0.047$ & $<0.001$ \\
\hline $\mathrm{R}_{(\mathrm{m})}^{2}$ & & 0.016 & & & 0.002 & & & 0.002 & & & 0.009 & \\
\hline $\mathrm{R}_{(\mathrm{c})}^{2}$ & & 0.049 & & & 0.005 & & & 0.030 & & & 0.042 & \\
\hline
\end{tabular}

$\beta$, beta coefficient; CI, confidence interval. Statistical significance set at $P<0.05$

Intercepts represent a draw and playing home. 
Table 2. (Continued)

\begin{tabular}{|c|c|c|c|c|c|c|c|c|c|c|c|c|}
\hline \multirow[b]{2}{*}{ Fixed effects } & \multicolumn{3}{|c|}{ Sustained Threat } & \multicolumn{3}{|c|}{ Fast Tempo } & \multicolumn{3}{|c|}{ Crossing } & \multicolumn{3}{|c|}{ High Pressure } \\
\hline & $\beta$ & $95 \% \mathrm{CI}$ & $P$ & $\beta$ & $95 \% \mathrm{CI}$ & $P$ & $\beta$ & $95 \% \mathrm{CI}$ & $P$ & $\beta$ & $95 \% \mathrm{CI}$ & $P$ \\
\hline Intercept & 0.080 & $0.071,0.088$ & $<0.001$ & 0.033 & $0.027,0.040$ & $<0.001$ & 0.174 & $0.164,0.183$ & $<0.001$ & 0.076 & $0.073,0.080$ & $<0.001$ \\
\hline Match status (-2 or more) & 0.020 & $0.013,0.027$ & $<0.001$ & 0.006 & $0.002,0.011$ & 0.009 & 0.049 & $0.037,0.060$ & $<0.001$ & 0.002 & $-0.005,0.009$ & 0.544 \\
\hline Match status (-1) & 0.017 & $0.011,0.022$ & $<0.001$ & 0.002 & $-0.001,0.006$ & 0.250 & 0.045 & $0.036,0.054$ & $<0.001$ & -0.001 & $-0.006,0.003$ & 0.602 \\
\hline Match status $(+1)$ & -0.011 & $-0.016,-0.006$ & $<0.001$ & $<0.001$ & $-0.003,0.004$ & 0.859 & -0.048 & $-0.057,-0.040$ & $<0.001$ & -0.009 & $-0.013,-0.004$ & $<0.001$ \\
\hline Match status (+2 or more) & -0.010 & $-0.017,-0.003$ & 0.007 & 0.012 & $0.007,0.016$ & $<0.001$ & -0.045 & $-0.057,-0.033$ & $<0.001$ & -0.011 & $-0.018,-0.004$ & 0.003 \\
\hline Venue (away) & -0.018 & $-0.026,-0.014$ & $<0.001$ & -0.004 & $-0.006,-0.001$ & 0.006 & -0.040 & $-0.046,-0.033$ & $<0.001$ & -0.010 & $-0.013,-0.006$ & $<0.001$ \\
\hline Quality opposition & -0.001 & $-0.002,-0.001$ & $<0.001$ & -0.001 & $-0.001,-0.001$ & $<0.001$ & -0.002 & $-0.003,-0.001$ & $<0.001$ & $-<0.001$ & $-0.001,-<0.001$ & 0.019 \\
\hline Match status $(-2$ or more $) *$ Quality opposition & - & - & - & - & - & - & - & - & - & $<0.001$ & $-0.001,0.001$ & 0.831 \\
\hline Match status $(-1) *$ Quality opposition & - & - & - & - & - & - & - & - & - & $-<0.001$ & $-0.001,0.001$ & 0.528 \\
\hline Match status $(+1) *$ Quality opposition & - & - & - & - & - & - & - & - & - & -0.001 & $-0.001,<0.001$ & 0.051 \\
\hline Match status ( +2 or more) $*$ Quality opposition & - & - & - & - & - & - & - & - & - & -0.001 & $-0.002,-<0.001$ & 0.004 \\
\hline Venue (away) * Quality opposition & - & - & - & - & - & - & - & - & - & - & - & - \\
\hline Random effects & $\beta$ & $95 \% \mathrm{CI}$ & $P$ & $\beta$ & $95 \% \mathrm{CI}$ & $P$ & $\beta$ & $95 \% \mathrm{CI}$ & $P$ & $\beta$ & $95 \% \mathrm{CI}$ & $P$ \\
\hline Match & $<0.001$ & $<0.001,<0.001$ & 0.101 & $<0.001$ & $<0.001,<0.001$ & 0.012 & $<0.001$ & $<0.001,0.001$ & 0.021 & $<0.001$ & $<0.001,<0.001$ & $<0.001$ \\
\hline Match status & $<0.001$ & $<0.001,0.001$ & $<0.001$ & $<0.001$ & $<0.001,<0.001$ & $<0.001$ & $<0.001$ & $<0.001,0.001$ & 0.009 & - & - & - \\
\hline Quality opposition & $<0.001$ & $<0.001,<0.001$ & $<0.001$ & $<0.001$ & $<0.001,<0.001$ & $<0.001$ & $<0.001$ & $<0.001,<0.001$ & $<0.001$ & $<0.001$ & $<0.001,<0.001$ & $<0.001$ \\
\hline Team & $<0.001$ & $<0.001,0.001$ & 0.004 & $<0.001$ & $<0.001,<0.001$ & 0.006 & $<0.001$ & $<0.001,0.001$ & 0.22 & $<0.001$ & $<0.001,<0.001$ & 0.043 \\
\hline Match status & - & - & - & - & - & - & - & - & - & - & - & - \\
\hline Residuals & 0.037 & $0.036,0.037$ & $<0.001$ & 0.020 & $0.020,0.020$ & $<0.001$ & 0.128 & $0.127,0.130$ & $<0.001$ & 0.038 & $0.037,0.038$ & $<0.001$ \\
\hline $\mathrm{R}_{(\mathrm{m})}^{2}$ & & 0.006 & & & 0.003 & & & 0.008 & & & 0.001 & \\
\hline $\mathrm{R}^{2}{ }_{(\mathrm{c})}$ & & 0.026 & & & 0.022 & & & 0.015 & & & 0.005 & \\
\hline
\end{tabular}

$\beta$, beta coefficient; $\mathrm{CI}$, confidence interval. Statistical significance set at $P<0.05$.

Intercepts represent a draw and playing home. 